\section{Observations on} introducing a paediatric

oncology nursing focus in a post-RN BScN program

\author{
By Gail M. Lindsay
}

\section{Abstract}

This article highlights the two-year process of developing and implementing a paediatric oncology nursing focus in a post-RN BScN program. A partnership between nurses, parents of children with cancer, other cancer care providers, funders and McMaster University School of Nursing grew out of the vision of the Paediatric Oncology Group of Ontario and its nursing committee. The author was the nurse educator/consultant to the project and offers observations on creative post-RN course development, delivery and system change. Specific clinical expertise is the foundation of excellent mursing practice and is, therefore, a credible focus for degree education. The development and initiation of the first North American paediatric oncology nursing focus in a post-RN BSCN program was funded by the Max Bell Foundation and the Richard and Jean Ivey Fund.

\section{Background}

In the fall of 1992, the Paediatric Oncology Group of Ontario (POGO) invited applications for the consultant position of nurse educator. The successful candidate would have the mandate, in collaboration with relevant partners, to investigate, develop and implement baccalaureate-level paediatric oncology nursing courses. This was a major step towards realizing the vision of the POGO nursing committee. In a 1988 provincial needs assessment related to the care of children with cancer, they had identified their priority as degree-linked, province-wide nursing education in paediatric oncology. The executive director of POGO was successful in obtaining funding, from the Max Bell Foundation and the Richard and Jean Ivey Fund, for the two-year, part-time project. She also worked closely with two paediatric and education nursing leaders who saw the benefits for nurses and their clients in this educational innovation.

There seemed to be an exciting confluence between POGO's dream, the funding, the players

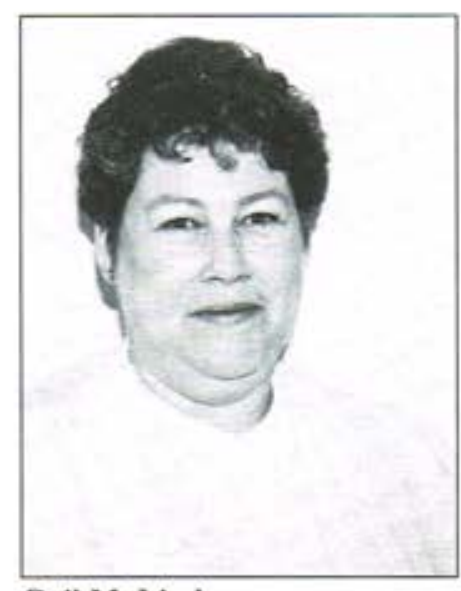

Gail M. Lindsay already involved and the factors in the university nursing environment that included the possibility of looking at clinically focused baccalaureate education. "Research suggests that early clinical specialization in one area might be extremely advantageous in that it would give students an opportunity to learn about the process of acquiring advanced clinical knowledge... acquiring advanced levels of skill in one speciality area would teach the student what is involved in acquiring advanced skills in general" (Benner, 1984, p.185).

\section{Planning process}

In September of 1992 the nurse educator/consultant was hired and began to meet with all the people identified who would have something useful to say about paediatric oncology nursing, curriculum development in general, educational program delivery and evaluation. The meetings occurred over several months and took her to Sudbury, London, Hamilton, Newmarket, Ottawa, Kingston and Tornnto. Nursing colleagues in practice, education and administration, in hospital, community and university settings, all were generous with their time and ideas about this educational innovation.

She also met with parents of children with cancer, other cancer care providers, academics and POGO committees. There were three observations from these meetings that served as touchstones throughout this project, namely:

- Even very experienced nurses want to know the rationale for the interventions they offer to children with cancer and their families - they want to be able to critique what is done and create caring and healing practices anew. As Benner comments in The Primacy of Caring: "the nurse is on the forefront of knowledge development, and educational practices need to prepare the nurse to engage in a dialogue with (their) practice" (1989, p.402).

- Parents of children with cancer poignantly discussed the roles of the nurse $(s)$ who were fundamental to their management of themselves,

\section{OBSERVATIONS SUR L'INTRODUCTION D'UN PÔLE ONCOLOGIQUE DANS UN PROGRAMME DE B.SC.INF. POST-DIPLÔME D'INFIRMIĖRE}

\section{ABRÉGÉ}

Cet article décrit le processus de deux ans qui a vu l'élaboration et la mise en oeuvre d'un pôle en soins infirmiers en oncologie pédiatrique au sein d'un programme de B.Sc.Inf. post-diplôme d'infirmière. C'est le POGO (Groupe d'oncologie pédiatrique de l'Ontario) et son comité des soins infirmiers qui ont pensé ce partenariat entre les infirmières, les parents d'enfants souffrant du cancer, d'autres prestataires de soins aux cancéreux, les organismes de financement et l'École des Sciences infirmières de l'Université McMaster. L'auteure était conseillère pour le projet à titre d'infirmière enseignante et elle offre ses observations sur une approche créative de l'élaboration des cours post diplôme, de leur prestation et du changement du système. Une expertise clinique spécifique est à la base de l'excellence de la pratique infirmière et peut donc faire partie intégrante de l'éducation menant à un diplôme universitaire. C'est la Fondation Max Bell et le Fonds Richard \& Jean Ivey qui ont assuré le financement de l'élaboration et de la mise en oeuvre du premier pôle en soins infirmiers en oncologie pédiatrique au sein d'un programme de B.Sc.Inf. post-diplôme d'infirmière, une première en Amérique du Nord.

Gail M. Lindsay, RN, MSN, "Idea Animator" provides project leadership and design as an independent consultant. As well, she is currently Program Manager for Continuing Education/Nursing at Ryerson Polytechnical University, and teaches at McMaster University School of Nursing. 
their child and family at a time of crisis - expert in practice (knowing what to do), teacher (knowing what is happening and what comes next), interpreter of the system, gatekeeper to other health providers, friend and ally.

- Educators recognized the expertise of nurses in paediatric oncology practice and advised that the "new" education piece should build on and augment that experience with scholarly skills, evidence-based practice, analysis and research.

Volunteers from the site visits formed an advisory group for the paediatric oncology nursing curriculum (PONC). The members were a parent of a child with cancer, nurses from paediatric oncology units and paediatric units in hospitals, universities and visiting nursing agencies. This group provided expert advice, feedback and many hours of thoughtful planning to the project.

An active subcommittee of the advisory group suggested project goals, created draft curriculum material including case studies, and kept the process rooted in the realities of nursing children with cancer and their families.

The consultant met with the deans and directors of the schools of nursing at POGO centre universities. They were all interested in contributing to the planned initiative.

The associate dean of health sciences (nursing) at McMaster University School of Nursing saw the potential for clinically-focused baccalaureate education. Based on her past work with the Canadian Nurses Association specialization process and with nurse practitioner research, she was willing to facilitate POGO's development of the project.

\section{Gathering support}

It was imperative to have a credible product to take to the other POGO centre universities. The purpose in approaching the other schools of nursing was twofold: To obtain potential sites for offering the courses and to assure credit transferability/fit with existing degree programs.

Synchronicity continued to be evident between the environment and this project. The Canadian Association of University Schools of Nursing statement on baccalaureate education proposed that "curricula may be designed to focus learning in one area of practice at the baccalaureate level" (1994). In addition, the primary care nurse practitioner role and education were under discussion in nursing circles and at the Ontario Ministry of Health, and the proposed education for the primary care nurse practitioner was at the baccalaureate level.

The scene was set for movement away from generic $\mathrm{BS} \mathrm{cN}$ studies, especially in the post- $\mathrm{RN}$ programs, to more focused or specialized study.

After collecting a great deal of print material about the state of cancer education in the world, the consultant could find no evidence of a paediatric oncology nursing curriculum at the baccalaureate level. However, an astute clinical educator in paediatric oncology at the Toronto Hospital for Sick Children (HSC) alerted her to the existence of the first year of a program that linked the College of Health in Bristol, England with the University of the West of England. Two students from the U.K. program were guests at HSC, and the educator/consultant was able to interview them about the collaborative certificate program developed by their tutor, Helen Langton.

The coordinator of the post-RN BScN program at McMaster University and the educator/consultant visited the Bristol program in the fall of 1993. A proposal about the content and delivery of degree-credit paediatric oncology nursing courses was then submitted to the McMaster University School of Nursing Undergraduate Nursing Education Committee for their consideration.
Figure One: McMaster University, School of Nursing, Paediatric oncology focus

\section{NURSING 3P03 NURSING CONCEPTS IN HEALTH AND ILLNESS III}

Bio-psychosocial sciences and nursing theory are integrated and applied to health care situations through problem-based learning. Concepts and theories will focus on assisting the child, family and community in responding to the oncological process. Three hours (lecture/problem-based tutorials); one term. Prerequisite: Registration in Paediatric Oncology Program.

\section{HTH SCI $3 \mathrm{LO2}$ INTRODUCTION TO THE RESEARCH PROCESS}

Introduction to principles and methods of the clinical research process. Concepts of research design, implementation, analysis and application to health care settings particularly paediatric haematology-oncology sites are studied. Two hours (lectures, tutorials); one term. Prerequisite: Registration in the Paediatric Oncology Program.

\section{HTH SCI 3A03 CRITICAL APPRAISAL}

A reinforcement of the principles of clinical research and statistical inference, with particular emphasis on critical assessment of evidence as presented in the health sciences literature particularly related to the care of children with cancer and their families.

Two hours (problem-based tutorial) and two hours (self-guided study); one term. Prerequisite: Registration in the Paediatric Oncology Program and completion of $\mathrm{Hth} \mathrm{Sci} 3 \mathrm{LO2}$

\section{NURSING 3V05 THEORIES AND SKILLS FOR PRIMARY HEALTH CARE}

Advanced theories and skills in client assessment and therapeutic communication relevant to hospital-based secondary and tertiary care and community-based oncology health care. This course is evaluated on a "Pass/Fail" basis. Five hours (problem-based tutorials); one term. Prerequisite: Registration in the Paediatric Oncology Program.

\section{NURSING 3W05 GUIDED NURSING PRACTICE I}

An applied nursing practice experience in a hospital or community-based paediatric haematology-oncology setting with an emphasis on the development of expanded role skills in areas such as illness-response, health maintenance and promotion, client education, client assessment and client treatment and support. This course is evaluated on a "Pass/Fail" basis. Eight hours (clinical lab), two hours (tutorials); one term. Prerequisite: Nursing 3V05 and registration in the Paediatric Oncology Program.

\section{NURSING 3Q03 NURSING CONCEPTS IN HEALTH AND ILLNESS IV}

A problem-based course in which students integrate theories from biological, physical, psychological, social and nursing sciences and apply them to paediatric haematology-oncology situations. A continuation of Nursing 3P03. Three hours (lecture/problem-based tutorials); one term. Prerequisite: Registration in the Paediatric Oncology Program. 


\section{The proposal}

The suggestion was that the paediatric oncology nursing courses could be adaptations or substitutes for existing, related $\mathrm{BScN}$ courses in the post-RN program. The major elements in that report included: - a request that the school of nursing recognize the paediatric oncology nursing focus within their post-RN BScN program

- that course material specific to paediatric oncology nursing (either new or adapted) be utilized in the focused curriculum

- that the timeframe in which the courses were to be delivered be consolidated for employed nurses. For instance, nurses could attend on weekends or six-hour days every two weeks, instead of three hours a week for 13 weeks.

- that a work study format or exchange system be utilized so that nurses would not need to take a leave of absence or use holiday time to apply their theoretical learning. Work study is academically effective (Eifert \& Lindsay, 1994).

- that students be able to register for the package of paediatric oncology nursing courses without applying to the BScN program. The author's experience is that this allows nurses to take courses that are immediately relevant to their practice and achieve academic confidence. The decision to apply to and complete their degree in nursing will be facilitated by their success in these courses.

System movement relies on the good will of people who do not have to get involved at all. There was no compelling tangible reason for McMaster to get involved in the paediatric oncology curriculum. Nurses already engaged in paediatric oncology clinical work were clear about the benefits of focused education, but that is not always enough incentive to change a system. However, the academic leaders in the school of nursing saw both the opportunity to shift nursing education in the direction of clinical focus at the baccalaureate level and the advantages of working with a funded partner. The larger scope of this project was attractive as it included provincial and national distance education strategies and access to larger nursing specialities.
The coordinator of the post-RN program at McMaster supported the implementation of this educational innovation and was able to act as an internal champion on its behalf. Once approval was obtained, operationalizing the project was straightforward. The paediatric oncology nursing focused package includes two problem-or case-based learning courses, two research and critical appraisal courses, an assessment and therapeutic communication course and a clinical practice term. The recommended accessibility elements were also accepted. (See Figure One).

The other piece of work fundamental to the implementation of the curriculum involved finding money to hire faculty, refine the curriculum, teach it and evaluate the students. An assistant professor with paediatric oncology nursing experience was available. Happily, the original funders allowed unspent funds to be used in the pilot implementation. In addition, the Hospital for Sick Children Foundation contributed significant dollars.

Separate monies were sought to develop an cvaluation methodology for the curriculum. A professor in the school of nursing conducted a multi-stage process of evaluation.

\section{Evaluation}

Students participated in questionnaires, interviews and clinical skill demonstrations in the first month of the first course. These measures will be repeated at the end of the six courses to ascertain professional practice and personal development changes. Multi-centre research is also underway as the Bristol program is now utilizing the McMaster evaluation package.

\section{Process insights}

Calm, courteous persistence was the primary attitude and behaviour in the consultant's role. Key strategies included staying focused on the ultimate goal, avoiding detail overload and staying in touch with strategic partners for updates and feedback.

When all the players in a situation are busy and there are many

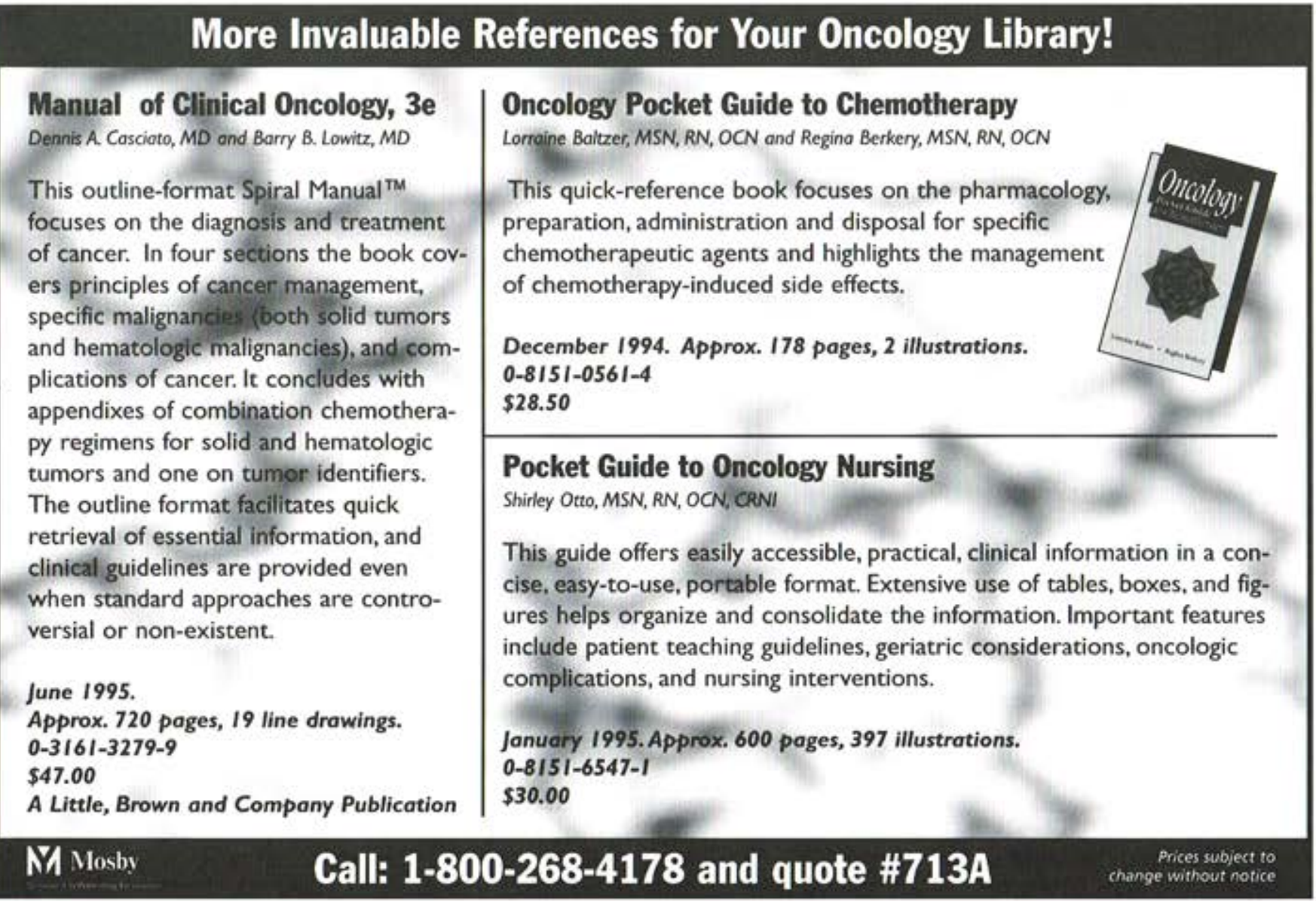


administrative/bureaucratic hurdles to face in order to implement someone else's change, it is important to establish relationships and credibility that reduce the consultant's outsider status. In retrospect, meeting personally with the internal committees or working sessionally in the generic $\mathrm{BScN}$ program may have influenced the acceptance of the proposal in a shorter timeframe.

There is a place for waiting during a project like this. While the actual task could be done in a shorter period of time, the necessary process and emotional/relational adjustments take much longer.

During the second winter of the project, there was a lull in the activities of curriculum planning which felt awkward until the consultant realized it was because the project was not in her hands at that point. She could respond to requests for information or create new submissions to different committees, but could not direct the internal process. This felt like a yeast process in bread-making - all that can be done is done and one needs to go away while the ingredients come together to create their own product.

\section{Funding initiatives}

Concurrent with the curriculum planning, the executive director of POGO, the associate dean from McMaster and the project consultant contacted pharmaceutical company representatives about their potential involvement with the project. A computer-assisted learning package was funded by POGO and Glaxo Canada. Distance education modalities have been planned for provincial and national accessibility to the courses.

Astra Pharma Inc. has made their video conferencing facilities available to the faculty and students in the paediatric oncology nursing courses.

\section{Implementation}

"Letting go" was the final challenge by the end of the second summer. If the project was to live at the university and become internalized as part of its curriculum, the project needed to pass fully into the hands of the faculty. That required loosening earlier ties to the project - POGO's sense of navigating, and the consultant's emotional and time commitment. It also required a realization that while the original vision or mandate had been achieved, it would transmute in the next stages. Other options and opportunities would grow from the original vision and they would develop in other hands.

Sixteen paediatric oncology nurses were selected to register for the first class in September 1994. They will now be able to examine their experience, compare it to peer and literature accounts of practice, analyze their effectiveness and use knowledge and guided intuition to plan caring interventions.

As a bridging strategy, the associate dean of health sciences (nursing) at McMaster University hired the educator/consultant to support the assistant professor who is modifying and delivering several of the focused courses. The few hours a week involved have allowed her to provide contextual information, names of contacts, keep POGO updated and know first-hand of the progress of the initiative.

As her contract ends in the spring of 1995, the consultant has a sense of closure with her part in the project and the pleasure of knowing a second cohort of paediatric oncology nursing students will be admitted in the fall. (See Figure Two).

\section{Conclusions}

"Over a long period of time and even up to the present, there has existed an intense concentration on functional role development (education, research, administration) instead of clinical expertness (Christman, 1992, 111). A seachange is underway in post-RN education that raises the profile of clinical nursing expertise. The first North American paediatric oncology nursing focus exists in a BScN program due to POGO's vision and McMaster School of Nursing's leadership.

\section{Acknowledgements}

The author acknowledges with gratitude the contributions of many individuals to the success of this project, especially Corin Greenberg, Executive Director, POGO, Andrea Baumann, Associate Dean of Health Sciences (Nursing), McMaster University, and Barbara Love, Assistant Professor, McMaster University.

Figure Two: Proposed Paediatric Oncology Focus Time Line

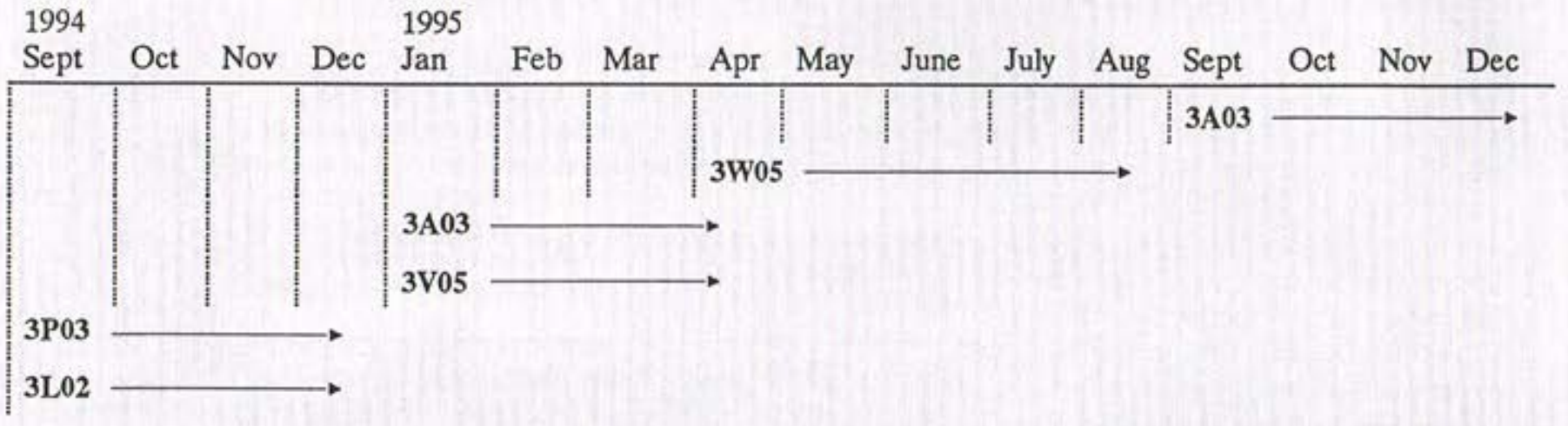

\section{References}

Benner, P. (1984). From novice to expert: Excellence and power in clinical nursing. Don Mills, ON: Addison-Wesley.

Benner, P., Wrubel, J. (1989). The primacy of caring. Don Mills, ON: Addison-Wesley.

Christman, L. (1992). Advanced nursing practice: Future of clinical nurse specialist. In L.H. Aiken and C.M. Fagin (Eds), Charting nursing's future: An agenda for the 1990s (108-120). Philadelphia: J.B. Lippincott.
Eifert, C, \& Lindsay, G. (1994). Ryerson's workstudy option. The Canadian Nurse, (4) 57-58.

Kalnins, I., Mahon, S., Casperson, D. (1994). Benefits of collaboration in continuing education: A partnership between a university provider and a nursing specialty organization. The Journal of Continuing Education in Nursing. 25(4), July/August, 148-151. 